\title{
Screening and identification of novel specific markers of breast cancer stem cells
}

\author{
TINGTING LIU ${ }^{1,2^{*}}$, BAOJIANG LI ${ }^{2 *}$, YUNYUN JIANG ${ }^{3}$, CHUNHUI ZHENG $^{4}$, \\ LI ZHANG $^{5}$ and YONGSHENG WANG ${ }^{1}$
}

${ }^{1}$ Breast Cancer Center, Shandong Cancer Hospital and Institute Affiliated to Shandong University, Jinan, Shandong 250117; Departments of ${ }^{2}$ Breast Surgery and ${ }^{3}$ Rehabilitation Medicine,

Tai'an Central Hospital, Tai'an, Shandong 271000; ${ }^{4}$ Department of Oncology Surgery, Weifang People's Hospital, Weifang, Shandong 261000; ${ }^{5}$ Department of Breast Oncology, Key Laboratory of Breast Cancer Prevention and Therapy, Tianjin Medical University Cancer Institute and Hospital/Ministry of Education, Tianjin 300060, P.R. China

Received August 15,2018; Accepted May 8, 2019

DOI: $10.3892 / \mathrm{ol} .2019 .10535$

\begin{abstract}
Breast cancer is the leading cause of death among women worldwide. Until recent years, triple negative breast cancer could be divided into 6 types according to different biomarkers with the development of sequence and microarray technology. However, these results rarely have therapeutic impact and still lack validation with the string criteria of clinical studies. Therefore, the present study aimed to screen novel markers of breast cancer stem cells and to verify the specificity in vitro and in vivo. In the present study, screening for phages specifically binding to breast cancer stem cells was performed, positive phage DNAs were extracted, and polypeptides were synthesized and labeled with FITC. The specificity of the polypeptides was identified in vitro and in vivo. Breast cancer stem cells were cultured and identified by flow cytometry. A phage random-peptide library was amplified and screened by culturing with breast cancer cells and breast cancer stem cells. The positive phage was identified by ELISA, and positive phage DNA was extracted. The DNA pellet was isolated and sent for external sequencing with the primer -96 gIII. Based on the sequencing results, a polypeptide was synthesized and labeled with FITC. The specificity to breast cancer stem cells was identified in vivo and vitro. Following three rounds of screening, the phage was enriched 200 -fold. Immunofluorescence demonstrated that two randomly selected phage clones, B8 and A3, had specific affinity to breast cancer stem cells. The results of the present study indicated that phage
\end{abstract}

Correspondence to: Professor Yongsheng Wang, Breast Cancer Center, Shandong Cancer Hospital and Institute Affiliated to Shandong University, 440 Jiyan Road, Jinan, Shandong 250117, P.R. China

E-mail: wangysh2008@aliyun.com

${ }^{*}$ Contributed equally

Key words: phage display, breast cancer stem cell, screening polypeptides that specifically bind to breast cancer stem cells were successfully screened through stem cell enrichment and phage display technology, which may be beneficial for targeted therapy and further study of breast cancer stem cells.

\section{Introduction}

Breast cancer is a malignant tumor with the highest incidence in women worldwide, and is the leading cause of mortality among women 40-55 years old in developed countries, including China (1). When diagnosed and treated, patients with early breast cancer may have positive outcomes, therefore, early detection is essential for decreasing breast cancer mortality (2). Although great progress has been made in the treatment of breast cancer, the effect is not satisfactory owing to its recurrence, metastasis and drug resistance in some patients (3). Cancer stem cell theory hypothesizes that cancer stem cells serve an important role in the formation and growth of cancer (4), and ignoring the treatment of cancer stem cells may result in tumor recurrence and metastasis (5). Phage display peptide library screening technology is a method for identifying high-specificity protein molecules (6). By screening with any target molecules, the sequence of the polypeptide or protein, which interacts with the target protein, is rapidly obtained $(7,8)$. It may also be used to analyze tumor epitopes to identify new tumor surface markers and prepare tumor vaccines $(9,10)$. Previous studies have demonstrated that phage display technology can identify multiple specific surface markers in triple negative breast cancer in human epidermal growth factor receptor 2-related breast cancer research $(7,11,12)$. In a breast cancer study, single-chain variable fragment 173, a specific binding protein capable of binding to the PM-1 breast cancer cell line, and Wiiger, a polypeptide specifically binding to breast cancer cells (13), were identified using phage display peptide library technology (14). Phage display technology is a mature technology for the screening of tumor-specific peptides that has been used to screen a variety of tumor-specific peptides $(8,15)$, but the application of this technology to identify breast cancer stem cell-specific peptides requires further investigation. 


\section{Materials and methods}

Cells, phage peptide library and host bacteria. Human breast cancer cell lines MDA-MB-231 and MCF-7, and human mammary gland cell line hs578bst (all purchased from the Type Culture Collection of the Chinese Academy of Sciences) were used in the present study. The bacteriophage random 12-peptide library kit (Ph.D. ${ }^{\mathrm{TM}}-12$ Phage Display Peptide Library kit; cat. no. E8110S) was purchased from New England BioLabs, Inc., and $100 \mu \mathrm{l}$ bacteriophage was stored in TBS containing $50 \%$ glycerol at $-20^{\circ} \mathrm{C}$. The following antibodies were used for the identification of breast cancer stem cells: Flow cytometry (FCM); FITC anti-human CD44 (cat. no. 338804; BioLegend, Inc.); phycoerythrin-conjugated anti-human CD24 (cat. no. 311106; BioLegend, Inc.); and Alexa Fluor 647 anti-human CD326 antibody (cat. no. 324212; BioLegend, Inc.).

Enrichment and identification of breast cancer stem cells. Cells were cultured at $37^{\circ} \mathrm{C}$ in $5 \% \mathrm{CO}_{2}$ in Dulbecco's modified Eagle's medium (DMEM; Gibco; Thermo Fisher Scientific, Inc.) containing $10 \%$ fetal bovine serum (FBS; Gibco; Thermo Fisher Scientific, Inc., cat. no. 16000-044), $100 \mathrm{U} / \mathrm{ml}$ penicillin and $100 \mathrm{U} / \mathrm{ml}$ streptomycin with regular media changes and frequent subculture. Stem cells were enriched in serum-free medium supplemented with epidermal growth factor, basic fibroblast growth factor and B27 supplement, and the microspheres were observed under an inverted microscope (Leica Microsystems, Inc., cat. no. CTR6000; magnification, x100). Centrifugation at $300 \mathrm{~g}$ for $10 \mathrm{~min}$ at $24^{\circ} \mathrm{C}$ was conducted to change the medium every 2-3 days. Following 1 week of serum starvation, cells were cultured medium with $10 \%$ FBS for one passage to remove dead cells. The cells were cultured alternately with 'serum and serum-free' culture medium to enrich the breast cancer stem cells, and were observed under an inverted microscope (Leica Microsystems, Inc., cat. no. CTR6000; magnification, x100). Subsequently, cells from the microspheres were labeled with following FITC-, PE-, Alexa Fluor 647-, conjugated mouse anti-human antibodies in fluorescence activated cell sorter buffer (BD Biosciences) for $30 \mathrm{~min}$ at room temperature. The FITC anti-human CD44 antibody (cat. no. 338804), PE anti-human CD24 antibody (cat. no. 311106) and Alexa Fluor 647(APC) anti-human CD326 (ESA) (cat. no. 324212) antibody were purchased from BioLegend, Inc. The CD $44^{+} / \mathrm{CD} 24 \%$ lowESA ${ }^{+}$phenotype cancer stem cells were sorted using a flow cytometer, then analyzed using FACS Canto II instruments (BD Biosciences) and BD Dive software 6.0 to determine the percentage of positive cells.

Screening phage random peptide library. The hs578bst cells, the MCF7 and MDA-MB-231 breast cancer cells and respectively enriched breast cancer stem cells were seeded in polylysine-coated petri dishes with serum-free DMEM for $2 \mathrm{~h}$ and blocked with $0.5 \%$ bovine serum albumin (BSA; Tianjin Umbrella Science \& Technology Co., Ltd.) for $1 \mathrm{~h}$. On day 1 , cells were trypsinized to obtain a single cell suspension and cells $\left(5 \times 10^{5}\right)$ were seeded on a polylysine-coated plate. Adherent cells were cultured in DMEM with $10 \%$ FBS and the stem cell microspheres were cultured in DMEM/Nutrient Mixture F-12
(Gibco; Thermo Fisher Scientific, Inc.) with 10\% FBS. Cells were cultured with serum-free medium the next day for $2 \mathrm{~h}$, blocked with $0.5 \%$ immunoglobulin G-free BSA-free medium for $1 \mathrm{~h}$ and washed with $0.1 \% \mathrm{TBS}+0.1 \%$ Tween-20 (TBST) buffer three times. For the first round of selection, $25 \mu \mathrm{l}$ of the original library was diluted with $1 \mathrm{ml}$ TBST buffer and added to the negative selection cells, MCF7 and MDA-MB-231. Subsequently, the cells were incubated at $37^{\circ} \mathrm{C}$ for $1 \mathrm{~h}$ and the supernatant was transferred to the negative selection cells. The phages were removed by washing with $1 \mathrm{ml} 0.2 \mathrm{M}$ glycine- $\mathrm{HCl}$ (pH 2.2) buffer. The cell supernatant was collected in a centrifuge tube after incubation for $10 \mathrm{~min}$ and neutralized with $150 \mu 1$ Tris- $\mathrm{HCl}$ ( $\mathrm{pH}$ 9.1). The product was amplified and titrated for the next round of selection. In the next round of selection, the total amount of each initial phage was $1 \times 10^{11}$, the time for positive selection was $30 \mathrm{~min}$ and $0.2 \%$ (v/v) Tween-20 was used for washing; other conditions remained unchanged. In the third round of screening, conditions were unchanged with two exceptions: The positive selection time was $15 \mathrm{~min}$ and $0.3 \%(\mathrm{v} / \mathrm{v})$ Tween-20 was used for washing.

Phage amplification. ER2738 Escherichia coli were incubated in $10 \mathrm{ml}$ lysogeny broth (LB)-tetracycline-10 (Oxoid, Ltd.) medium overnight to prepare for the second day of phage amplification. The ER2738 cell suspension was diluted in $20 \mathrm{ml} \mathrm{LB}$ medium at a ratio of 1:100, shaken and subsequently cultured at $37^{\circ} \mathrm{C}$ for $1-2 \mathrm{~h}$ to reach early logarithmic growth phase [optical density at $\left.600 \mathrm{~nm}\left(\mathrm{OD}_{600}\right), 0.3-0.4\right]$. The phage were added in $1 \times 10^{11} \mathrm{pfu}$ and cultured at $37^{\circ} \mathrm{C}$ with vigorous shaking by $200 \mathrm{rpm}$ for $4.5 \mathrm{~h}$. The culture product was transferred to a centrifuge tube and centrifuged at 10,000 $\mathrm{x} g$ for $10 \mathrm{~min}$ at $4^{\circ} \mathrm{C}$. The supernatant was transferred to another centrifuge tube and centrifuged again under the same conditions. The upper part $(80 \%)$ of the supernatant was transferred to a new tube $1 / 6$ volume of $\mathrm{PEG} / \mathrm{NaCl}$ was added and left to precipitate overnight at $4^{\circ} \mathrm{C}$. Subsequently, the sample was centrifuged at $10,000 \mathrm{x}$ for $15 \mathrm{~min}$ at $4^{\circ} \mathrm{C}$. The supernatant was discarded, the pellet was centrifuged briefly and the residual supernatant was aspirated. The pellet was resuspended in $1 \mathrm{ml}$ TBS, transferred to a microcentrifuge tube and centrifuged at $10,000 \mathrm{~g}, 4^{\circ} \mathrm{C}$ for $5 \mathrm{~min}$ to precipitate the residual cells.

The supernatant was transferred to a new centrifuge tube, re-precipitated with $1 / 6$ volume of $\mathrm{PEG} / \mathrm{NaCl}$ and incubated on ice for 15-60 min. Following centrifugation at $10,000 \mathrm{x} \mathrm{g}, 4^{\circ} \mathrm{C}$ for $10 \mathrm{~min}$, the supernatant was discarded and briefly centrifuged again. The residual supernatant was aspirated using a micropipette. The pellet was resuspended in $200 \mu 1 \mathrm{TBS}$ and centrifuged at $4^{\circ} \mathrm{C}, 10,000 \mathrm{x}$ g for $1 \mathrm{~min}$. The supernatant was subsequently transferred to a fresh tube as the amplification product.

Phage titration. The phage was titrated with a LB/isopropyl $\beta$-D-1-thiogalactopyranoside (IPTG)/5-bromo-4-chloro-3indolyl- $\beta$-D-galactoside (X-gal) tablet: ER2738 single colonies were inoculated in 5-10 ml LB medium, shaken and cultured to mid-logarithmic growth phase $\left(\mathrm{OD}_{600}, \sim 0.5\right)$. The upper agar was melted in the microwave and divided it into $3 \mathrm{ml}$ aliquots in sterilized tubes, one tube per phage dilution. The tubes were stored at $45^{\circ} \mathrm{C}$ for future use. A LB/IPTG/X-gal plate was prewarmed at $37^{\circ} \mathrm{C}$ for each phage dilution. A 10 -fold 
serial dilution of phage in LB was prepared. The titers were in the range of $10^{1}-10^{11}$. The phage at the logarithmic phase was divided into $200 \mu \mathrm{l}$ aliquots in microcentrifuge tubes, one tube per phage dilution. A total of $10 \mu \mathrm{l}$ phage was added in different tubes, mixed rapidly and thoroughly shaken. Subsequently, the samples were incubated at room temperature for 1-5 min. Infected cells were added to the $45^{\circ} \mathrm{C}$ prewarmed upper agar culture tube, mixed rapidly and put onto the $37^{\circ} \mathrm{C}$ prewarmed $\mathrm{LB} / \mathrm{IPTG} / \mathrm{X}$-gal plate. The plate was tilted to allow the spread of the upper agar. Following cooling for $5 \mathrm{~min}$, the plate was incubated overnight at $37^{\circ} \mathrm{C}$. The number of blue spots with $\sim 10^{2}$ plaques was counted and multiplied by the dilution fold to obtain the plaque forming unit (pfu) titer per $10 \mu \mathrm{l}$ phage.

Positive phage identification. The enriched breast cancer stem cells, MCF7 and MDA-MB-231, were seeded in 96-well plates $\left(1 \times 10^{4}\right.$ cells/well) with serum-free DMEM for $2 \mathrm{~h}$ following adherence. The cells were fixed with $4 \%$ paraformaldehyde at $24^{\circ} \mathrm{C}$ for $15 \mathrm{~min}$ and washed with PBS. The cells were treated with $0.1 \%$ Triton $\mathrm{X}-100$ for $10 \mathrm{~min}$ and washed with PBS $+0.5 \%$ Tween-20 (PBST) three times. Following $1 \mathrm{~h}$ of blocking with $2 \%$ PBS-BSA at $37^{\circ} \mathrm{C}$, the cells were incubated with the amplified monoclonal phage for $2 \mathrm{~h}$ at $37^{\circ} \mathrm{C}$ and washed three times with PBST. Following incubation at $24^{\circ} \mathrm{C}$ with horseradish peroxidase (HRP)-conjugated anti-M13 antibody (cat. no. 405210; BioLegend, Inc.; dilution, 1:5,000 in $2 \%$ PBS-BSA) for $1 \mathrm{~h}$ cells were washed with PBST three times. Then 3,3',5,5'-tetramethylbenzidine (TMB) was added to proceed with the chromogenic reaction. $\mathrm{HCl}$ was added to terminate the TMB chromogenic reaction and the absorbance was read at $450 \mathrm{~nm}$ using a microplate reader. A phage plaque was randomly selected as a control, and the value of OD phage clone/OD control $>2$ was regarded as positive. Normal breast cells (hs578bst), breast cancer and enriched breast cancer stem cells, MCF7 and MDA-MB-231, were seeded in a 24-well plate $\left(1 \times 10^{5}\right.$ cells/well), and a similar process was repeated using a DAB HRP chromogenic kit instead of TMB, and $\mathrm{HCl}$ was replaced with distilled water following a 10 min incubation. Cells were counterstained with Mayer's hematoxylin solution and observed under an inverted microscope (Leica Microsystems, Inc., cat. no. CTR6000; magnification, x100).

Positive phage sequencing. Single E. coli ER2738 colonies were inoculated into $20 \mathrm{ml} \mathrm{LB}$ medium, shaken and cultured at $200 \mathrm{rpm}, 37^{\circ} \mathrm{C}$ to early logarithmic growth phase. A total of $10 \mu \mathrm{l}$ positive phage clone KL-6 stock solution at $1 \times 10^{11} \mathrm{pfu}$ was added to the ER2738 solution, shaken and centrifuged at $37^{\circ} \mathrm{C}$ and $250 \mathrm{rpm}$ for $3.5 \mathrm{~h}$. Following centrifugation at $10,000 \mathrm{x} \mathrm{g}, 24^{\circ} \mathrm{C}$ for $5 \mathrm{~min}$, the supernatant was added to $1 / 6$ volume of $20 \%$ polyethylene glycol (PEG)/NaCl to precipitate at room temperature for $1 \mathrm{~h}$ and centrifuged at $10,000 \times \mathrm{gg}, 24^{\circ} \mathrm{C}$ for $10 \mathrm{~min}$. The supernatant was removed, and the precipitate was resuspended with $1 \mathrm{ml}$ TBS and stored at $4^{\circ} \mathrm{C}$. During plaque amplification, $500 \mu \mathrm{l}$ phage-containing supernatant was transferred to a new tube following the first centrifugation. A total of $200 \mu \mathrm{l} \mathrm{PEG} / \mathrm{NaCl}$ was added, and the mixture was inverted and mixed. Subsequently, the mixture was allowed to stand at room temperature for $10 \mathrm{~min}$. The sample was centrifuged at $10,000 \times \mathrm{g}, 24^{\circ} \mathrm{C}$ for $10 \mathrm{~min}$ and the supernatant was discarded. The sample was centrifuged briefly again, and the residual supernatant was aspirated. The pellet was completely resuspended in $100 \mu \mathrm{l}$ sodium iodide buffer, $250 \mu \mathrm{l}$ absolute ethyl alcohol was added and incubated at room temperature for 10 min to precipitate single stranded phage DNA. Following the incubation, the sample was centrifuged at $10,000 \mathrm{x} \mathrm{g}$, $24^{\circ} \mathrm{C}$ for $10 \mathrm{~min}$ and the supernatant was discarded. The precipitate was washed with $70 \%$ ethanol and briefly vacuum dried. The pellet was resuspended in $30 \mu 1$ Tris-EDTA and the resulting suspension was used as the template solution for sequencing. MDA-MB-231 cell clone B1-B10 sequences were as follows: B1, LYAVDLSPKSRY; B3, HLAVRPISTNSR; B4, ITRSYPPLPLPP; B5, TNSFHAIAGYQS; B6, TMHYKGTAASES; B7, YSDGVRAPRTVE; B8, TNSFHGIAGYQS; B9: KLTALVTTWPWT. As a control, two negative peptide sequences were obtained from the selected three blue plaques: B11, GMLSWTKERPNT; B13, NHKTINYQNDAT. MCF7 cell clone A1-A10 sequences were as follows: A1, DSMHHSLKPPYS; A2, FKPTWVVPINVA; A3, NPGTDLYRPPHN; A5, NPSRSGPANWPD; A8, HRTLDPQPLTHP; A9, VDWYDISRLRRT. As a control, two negative peptide sequences were obtained from the selected three blue plaques: A11, GSYTAYSSIATA; A13, SFHASMRPHTST. The sequencing primer was -96 gIII, 5'-HOCCCTCATAGT TAGCGTAACG-3' (Tianjin Purui Biological Engineering Co. Ltd).

Synthesis and determination of polypeptides in vitro. Polypeptides were synthesized based on the sequencing results and labeled with FITC. The breast cancer cells and breast cancer stem cells MCF7 and MDA-MB-231 were incubated at $24^{\circ} \mathrm{C}$ for $15 \mathrm{~min}$ with the polypeptides. Subsequently, the distribution of the FITC-tagged polypeptides was observed in different cell lines and images were captured under an inverted microscope (Leica Microsystems, Inc., cat. no. CTR6000; magnification, $\mathrm{x} 100)$.

Specificity identification of polypeptide in vivo. A total of 10 nude BALB/c female mice (6-8 weeks, average weight $20 \mathrm{~g}$ ) were used to establish an animal model of breast cancer with the approval of the Ethics Committee of Shandong Cancer Hospital and Institute. The mice were purchased from Nanjing Animal Center. The ad libitum-fed mice were kept at $22^{\circ} \mathrm{C}$ in a SPF environment (45\% humidity; 20 Pa pressure difference) with a 14/10 h light/dark cycle. MDA-MB-231 stem cells were centrifuged and the concentration of breast stem cells was adjusted to $1 \times 10^{8}$ cells $/ \mathrm{ml}$. The cells were implanted subcutaneously under the right breast pad of nude BALB/c mice. Palpable tumor nodules first appeared 3 weeks after tumor injection and they rapidly grew and reached $8-10 \mathrm{~mm}$ in diameter in 3 weeks. The polypeptide labeled with FITC (120 $\mu \mathrm{l}, 1 \mathrm{mMol}$ ) was injected into the tail vein of nude mice, and the mice were sacrificed by cervical dislocation and dissected after $2 \mathrm{~h}$. The tumor and liver control tissue were cut to $<1 \mathrm{~mm}$, added with PBS, moved to 12 -hole plate with cover glass, cultured at $37^{\circ} \mathrm{C}$ for $1 \mathrm{~h}$ in an incubator. Then, cells were fixed with $4 \%$ paraformaldehyde (Tianjin Umbrella Science \& Technology Co., Ltd. at $24^{\circ} \mathrm{C}$ for $1 \mathrm{~h}$, washed with PBS, then treated by $0.3 \%$ Triton (Tianjin Umbrella Science \& Technology Co., Ltd.) for $20 \mathrm{~min}$ and washed again with PBS. A total of $100 \mu 1$ DAPI (Sigma-Aldrich; 
Table I. Results of three rounds of phage screening and enrichment in MCF-7 breast cancer stem cells.

\begin{tabular}{lccc}
\hline Round & $\begin{array}{c}\text { Initial phage } \\
\text { volume }(\mathrm{pfu} / \mathrm{ml})\end{array}$ & $\begin{array}{c}\text { Elution phage } \\
\text { volume }(\mathrm{pfu} / \mathrm{ml})\end{array}$ & $\begin{array}{c}\text { Enrichment } \\
\text { rate }(\%)\end{array}$ \\
\hline Round 1 & $2.00 \times 10^{10}$ & $1.05 \times 10^{2}$ & 0.007 \\
Round 2 & $2.00 \times 10^{10}$ & $1.20 \times 10^{4}$ & 0.005 \\
Round 3 & $2.00 \times 10^{10}$ & $1.12 \times 10^{6}$ & 0.004 \\
\hline
\end{tabular}

Merck KGaA; cat. no. D9542) diluted as 10:1 by PBS contained 3\% BSA (Tianjin Umbrella Science \& Technology Co., Ltd.), was added and kept at $10 \mathrm{~min}$ to complete nuclear staining. The tumor and liver cells were examined using a microscope (Zeiss confocal Microscope 880; magnification, x60, excitation wavelength $488 \mathrm{~nm}$ ) and images were obtained.

\section{Results}

Breast cancer stem cell primary culture. The pretreated primary breast cancer cells were cultured overnight to adhere to the surface. Elongated flat cells were observed under a microscope. Following 30 days of serum and serum-free culture, the cells were suspended in the culture medium under the microscope and appeared bright and round (Fig. 1). The cells formed balloon-like shapes and were able to grow in complete medium. The volume and number of cells increased as the culture time increased (x100; Fig. 1).

Flow cytometry for breast stem cell identification. Breast cancer stem cells were sorted by flow cytometry to identify the $\mathrm{CD}_{4} 4^{+} / \mathrm{CD} 24 /$ lowESA ${ }^{+}$cell group. The average proportions of induced MCF7 and MDA-MB-231 breast cancer stem cells were 89.4 and $57.8 \%$, respectively (Fig. 2).

Screening and enrichment analysis of phage peptide library. The phage peptide library was subjected to three rounds of 'affinity-elutriation-amplification' affinity screening. Following three rounds of elutriation, the phage recovery rate increased and stabilized in the third round (Tables I and II), which indicated that the phage may specifically bind to human breast cancer cells. The third round of screening enriched the phage 200 times more compared with the first round, and the titer was monitored for screening products. A total of $10 \mu \mathrm{l}$ phage was titrated and the enrichment prior to and following each screening was compared. On the final round of titration, 10 blue plaques and two monoclonal phages were randomly selected.

Clone sequencing. A total of 10 clones were randomly selected from the final screening products and sequenced. In total, 10 positive clones were obtained through MDA-MB-231 and MCF7 screening, and eight and six sequencing results were obtained, respectively. The screening result was considered reliable and credible owing to the complexity of the cell surface. A total of six distinct polypeptide sequences with no similar or identical sequences were obtained in the 10 sequences from the MCF7 cell screening.
Table II. Results of three rounds of phage screening and enrichment in MDA-MB-231 breast cancer stem cells.

\begin{tabular}{lccc}
\hline Round & $\begin{array}{c}\text { Initial phage } \\
\text { volume (pfu/ml) }\end{array}$ & $\begin{array}{c}\text { Elution phage } \\
\text { volume (pfu/ml) }\end{array}$ & $\begin{array}{c}\text { Enrichment } \\
\text { rate (\%) }\end{array}$ \\
\hline Round 1 & $2.00 \times 10^{10}$ & $6.60 \times 10^{2}$ & 0.0441 \\
Round 2 & $2.00 \times 10^{10}$ & $7.60 \times 10^{4}$ & 0.0022 \\
Round 3 & $2.00 \times 10^{10}$ & $9.80 \mathrm{Ex} 10^{5}$ & 0.0015 \\
\hline
\end{tabular}

The results of the B8 positive clone sequencing were: 3'-TCA GAC GTT AGTAAT GAATTTTCTGTA TGGGATTTTGCTAAACAACTTTCAACAGTTTCGGC CGAACCTCCACCCGACTGATAACCCGCAATACCAT GAAAAGAATTAGTAGAGTGAGAATAGAAAGGTACC ACT AAAGGAATTGCGAATAAACCCTAAAAAAA-5'; the complementary sequence was 5'-ACTAATTCTTTTCAT GGTATTGCGGGTTATCAGTCG-3' (TNSFHGIAGYQS;). The results of the $\mathrm{A} 3$ positive clone sequencing were: $3^{\prime}-\mathrm{CCG}$ ACGTTAGTAAATGAATTTTCTGTATGGGATTTTGCT AAACAACTTTCAACAGTTTCGGCCGAACCTCCACCA TTATGAGGAGGACGATAAAGATCCGTACCAGGATTA GAGTGAGAATAGAAAGGTACCACTAAAGGAATTGCG AATAAAACCACGCTGTTTTGACCGCTCCGTACGCGA ACCTGCGGTCGTCCCCTTATTGATATGCTCGATCTC AGTGGTATTTGTCACGTTAACGCTAACATGAATCTC TCTGTTAGAGCGGATGTGTGAGGTTGTAGAAATTCC GTGTGTACTGCGGTGAGCAAATGTATCTTATGGGAC TGTAACTGTCCCGATGTGTTCTGGGAAATCACCACA TTACCCCAAGTTATTTAAGTGACATTCACTTCTGTT TTCGGCATGAACTTTCGCAAATGTCGCAGGATCTTCAT CTACCCAAACCTGTTGGTTCTTGCCAGATCTGTGTCTAT GCTCACCCTGGAATACGTAATCATGTCATAGCCGTTTC CTGTGGGAAACTGTTATCCGCTCACAATTCCACAAT-5'; the complete sequence was 5'-AATCCGGGTACGGATCTTT ATCGTCCTCCTCATAAT-3' (NPGTDLYRPPHN).

Determination of polypeptides. According to the sequencing results, the peptides were synthesized and labeled with FITC. The peptides were identified to be specific for breast cancer stem cells; the cells were observed and imaged under a fluorescence microscope following co-incubation in vitro.

Polypeptide B8 (sequenced twice) was able to specifically bind to the MDA-MD-231 stem cells without binding to the original MDA-MD-231 cells (Fig. 3A), whereas the negative control polypeptide B11 did not bind to the MDA-MD-231 stem cells or to the original MDA-MB-231 cells (Fig. 3B).

Polypeptide A3 (sequenced once) was able to specifically bind to the MCF7 stem cells without binding to the original MCF7 cells (Fig. 4A), whereas the negative control peptide A13 did not bind to the MCF7 stem cells or to the original MCF7 cells (Fig. 4B).

Determination of polypeptide $B 8$ distribution in nude mice. Tumor tissues and control livers tissues of the nude mice injected with MDA-MB-231 stem cells and polypeptide B8 were observed under a microscope. FITC labeling of B8 was 

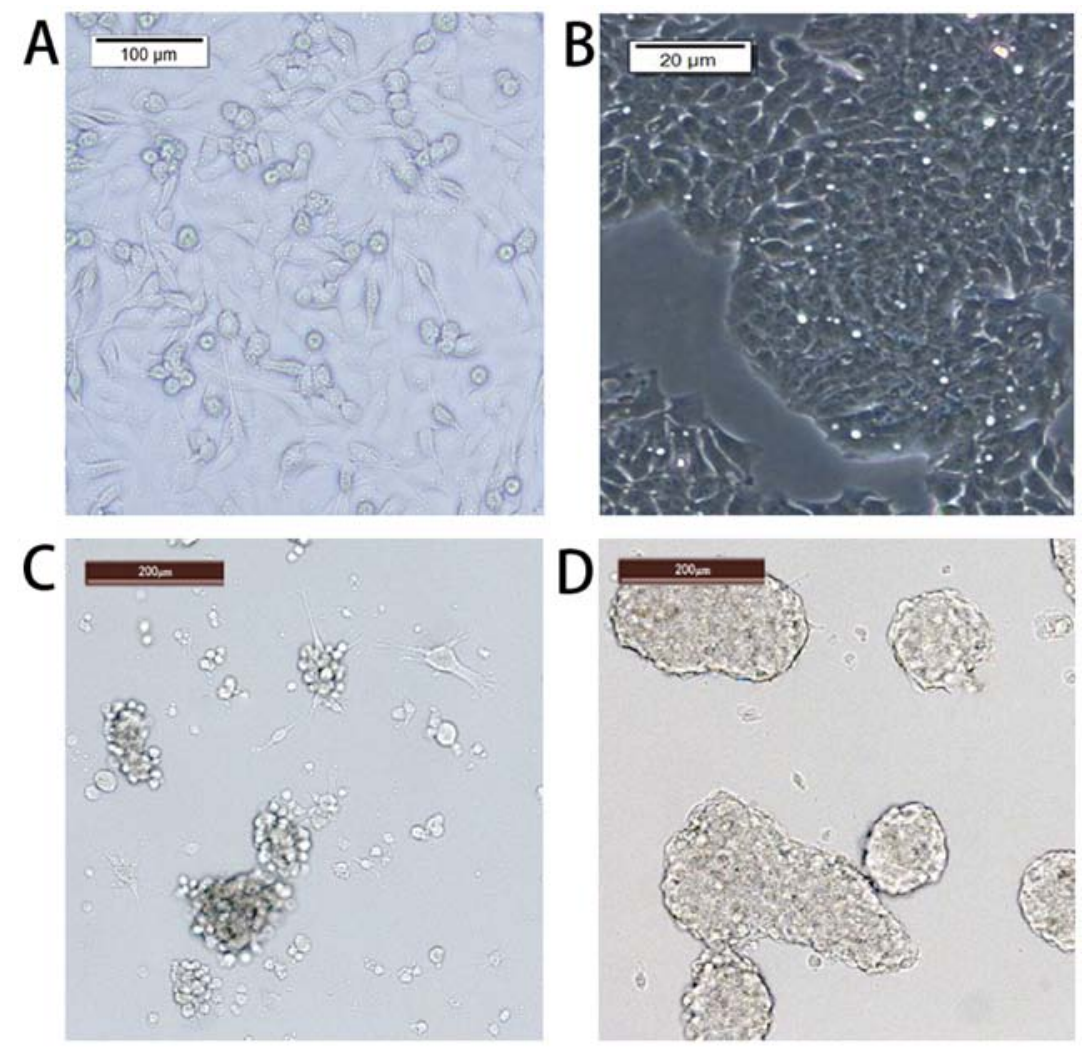

Figure 1. Breast cancer stem cells formed following culture using the 'serum and serum-free' method. Primary breast cancer cells MDA-MB-231 and MCF7 were cultured overnight to adhere to the surface. Elongated flat cells were observed under a microscope. (A) The common MDA-MB-231 breast cancer cell. (B) The common MCF7 breast cancer cell. Following 30 days of serum and serum-free culture, (C) MDA-MB-231 and (D) MCF7 breast cancer stem cells formed balloon-like shapes and were able to grow in complete medium. Magnification, x10.
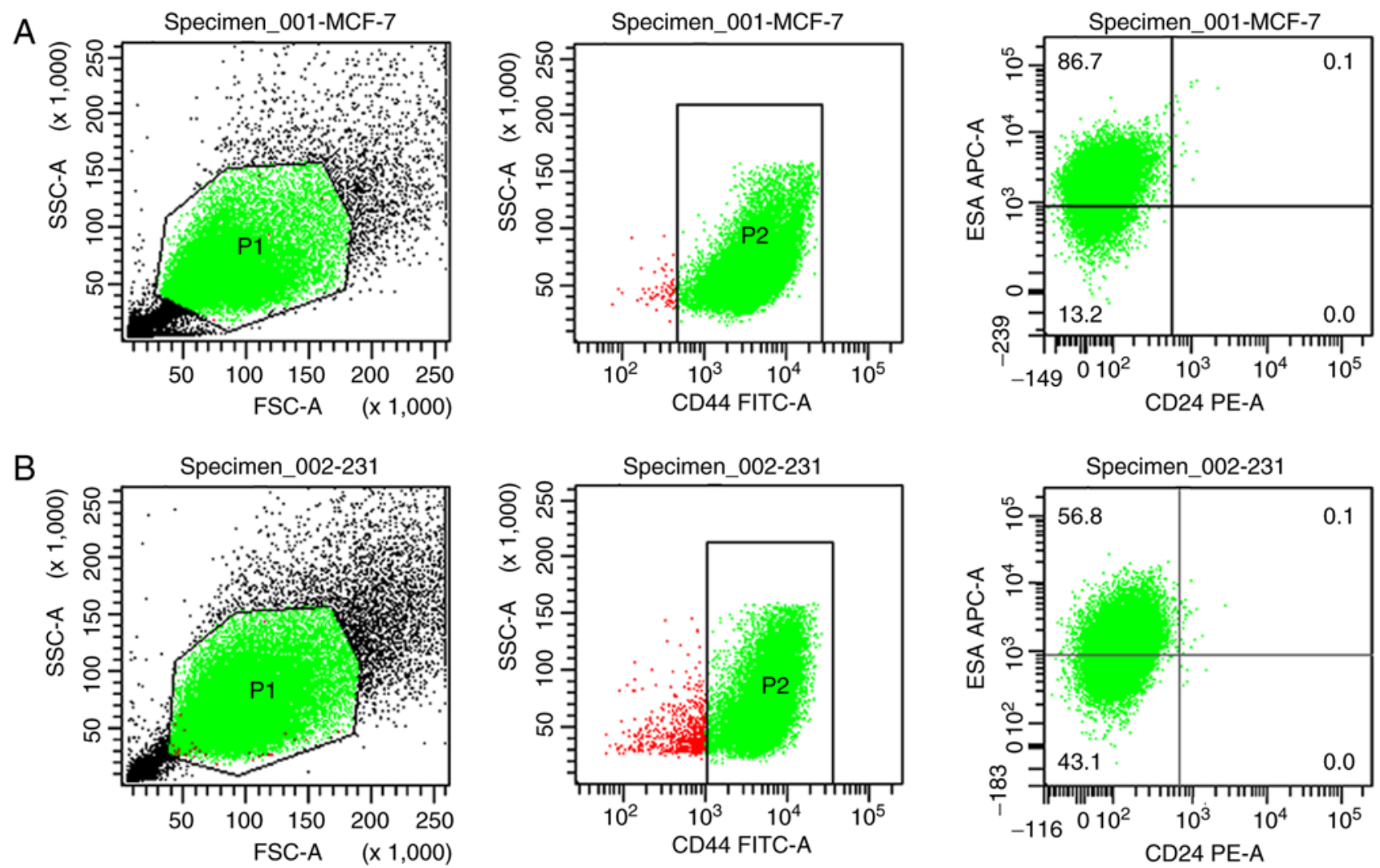

Figure 2. Flow cytometry results of breast cancer stem cells. (A) The average proportion of CD44 ${ }^{+} / \mathrm{CD} 24 /$ lowESA ${ }^{+} \mathrm{MCF} 7$ breast cancer stem cells was $89.4 \%$. (B) The average proportion of CD44 /CD24/lowESA ${ }^{+}$MDA-MB-231 breast cancer stem cells was $57.8 \%$. ESA APC, epithelial surface antigen allophycocyanin; FSC, forward scatter; P1, breast cancer stem cells; P2, CD44 ${ }^{+}$cells; PE, phycoerythrin; SSC, side scatter. 
A

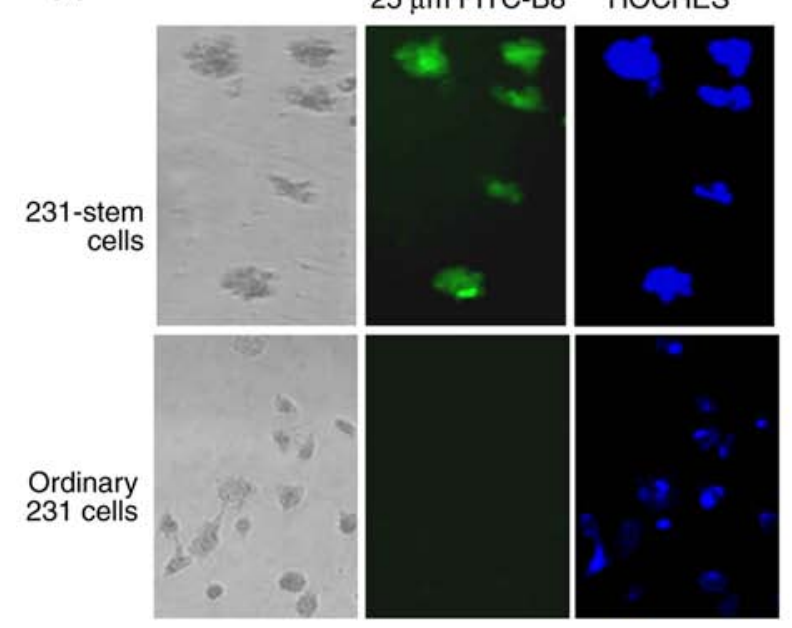

B

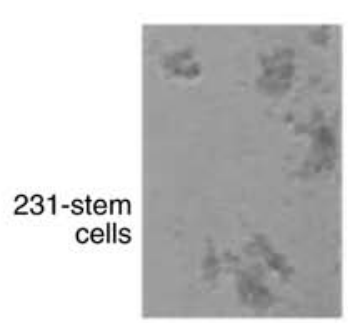

$25 \mu \mathrm{m}$ FITC CtriB11

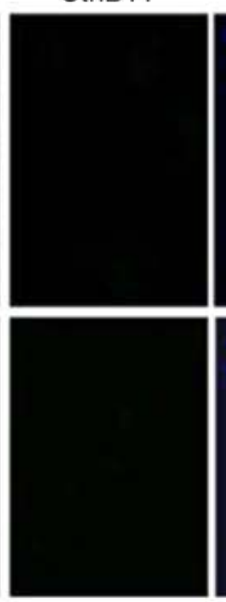

HOCHES

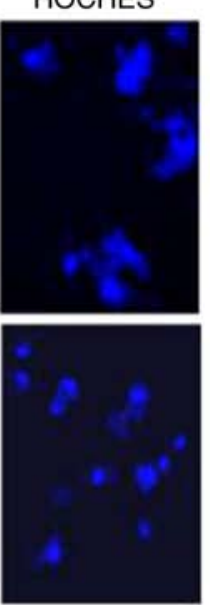

Figure 3. Specific binding of polypeptide B8 to MDA-MB-231 breast cancer stem cells and MDA-MB-231 breast cancer cells. (A) MDA-MB-231 breast cancer stem cells and MDA-MB-231 breast cancer cells were incubated with FITC-labeled polypeptide B8. FITC-labeled B8 exhibited specific binding to MDA-MB-231 breast cancer stem cells, but not to MDA-MB-231 breast cancer cells. (B) FITC-labeled control polypeptide B11 did not bind to MDA-MB-231 breast cancer stem cells or MDA-MB-231 breast cancer cells.

A

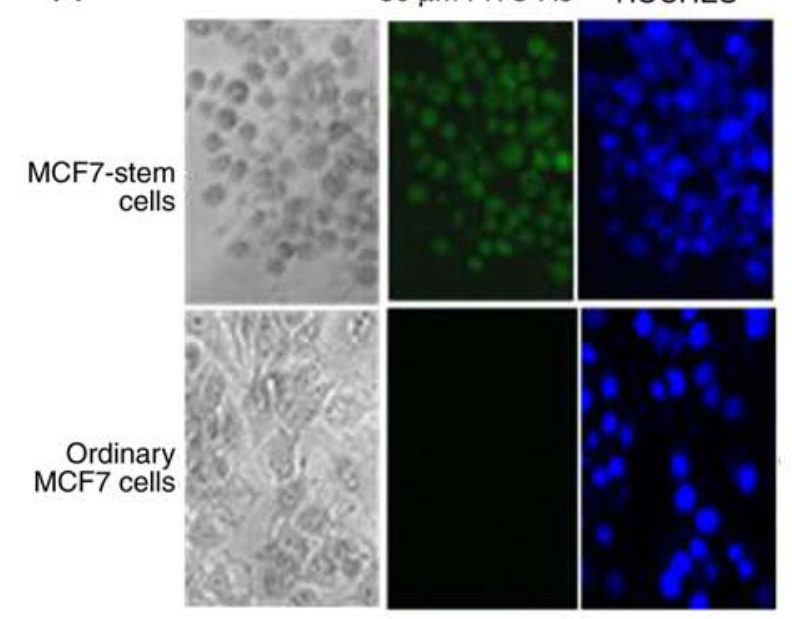

B
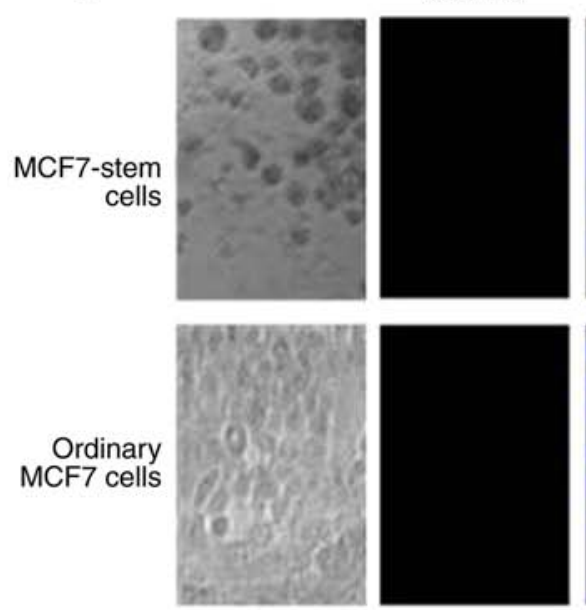

HOCHES
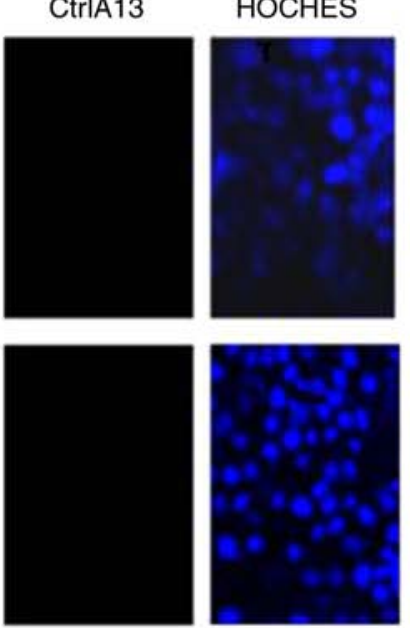

Figure 4. Specific binding of polypeptide A3 to MCF-7 breast cancer stem cells and MCF-7 breast cancer cells. (A) MCF7 breast cancer stem cells and MCF-7 breast cancer cells were incubated with FITC-labeled A3. FITC-labeled A3 exhibited specific binding to MCF7 breast cancer stem cells, but not to MCF7 breast cancer cells. (B) FITC-labeled control polypeptide A13 did not bind to MCF7 breast cancer stem cells and MCF7 breast cancer cells.

abundant in tumor tissue, but not detected in control liver tissue (Fig. 5A and B, respectively).

\section{Discussion}

Traditional treatments of breast cancer include surgery, chemotherapy, hormonal therapy, target therapy, radiotherapy and immunotherapy (16). Although there have been improvements in the survival of patients with breast cancer using multi-modal methods, recurrence and metastasis still occur in a number of patients (1). Breast cancer stem cells serve a decisive role during the process of tumorigenesis and recurrence (17). Previous studies on breast cancer stem cells have investigated their relationship with viruses (18), expression of estrogen (19) and radiation treatment (20). The generation of highly selective ligands to breast cancer cells is important for precise diagnosis and treatment. The screening of phage display libraries provides an economic and easy method to generate a variety of selective and highly specific ligands to target cells (18) The development of targeted peptides for breast cancer stem cells may reduce drug dosage and unwanted effects of chemotherapy drugs on normal cells, and may represent a radical method to cure breast cancer (14).

In the present study, the 'serum and serum-free' culture method, also known as dual-subtract biopanning, was used to enrich breast cancer stem cells. This method can reduce the disadvantages of the serum-free culture method, which does not enrich a large number of stem cells, and has minimal damage to stem cells. In breast cancer, a population of CD44 cancer stem cell surface markers that is highly enriched for cancer-initiating cells has been isolated (21). The CD44+ 
A

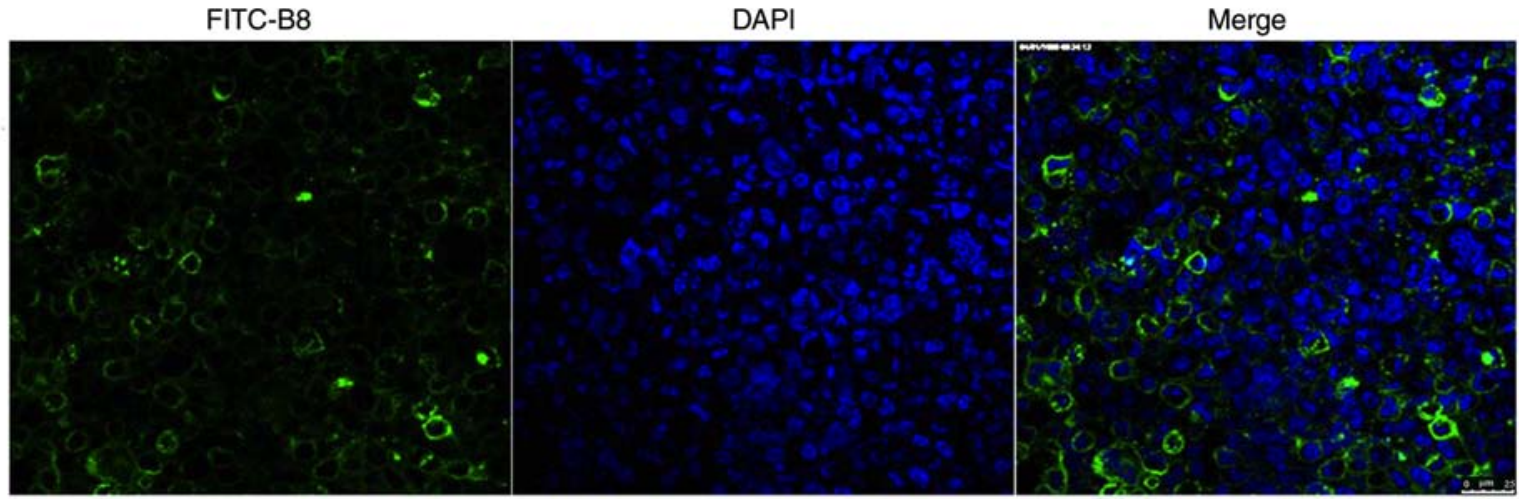

B

FITC-B8

DAPI

Merge
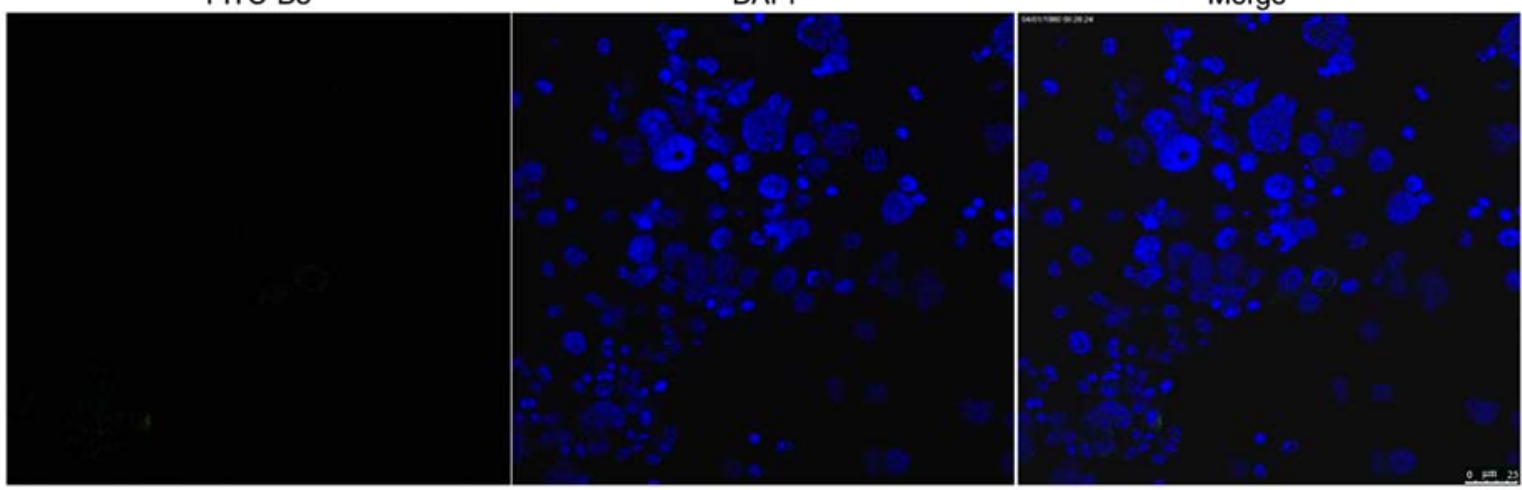

Figure 5. Distribution of FITC-labeled polypeptide B8 in nude mice. (A) FITC-labeled polypeptide B8 was abundant in tumor tissue. (B) FITC-labeled polypeptide B8 was not observed in the control liver tissue. Nuclei were stained with DAPI; magnification, x60.

marker is one of the most promising markers for early breast cancer detection. CD133 is one of the numerous markers used for screening targets for cancer stem cells, but the roles of CD133 and its natural ligand in breast cancer stem cells have not yet been determined. CD44 and CD24 were selected as cell surface markers for breast cancer stem cells following enrichment, and their expression was detected by flow cytometry.

Peptides have advantages as detection probes for imaging and targeting (17). They have a smaller size and better tissue penetration compared with other antibodies. Furthermore, the specific binding of tumor cells using high affinity and highly selective peptides combined with traditional chemotherapeutics enables the use of low doses, eliminating the toxic effects of chemotherapeutics (14). The display of peptide libraries on the surface of bacteriophages is a standard technology for selecting peptides with specific binding properties (22).

Park et al (14) used a peptide library to screen novel diverse peptides that bind to CD44 with high affinity, however, this study not only screened the phage specifically binding to breast cancer stem cells, but also identified their specificity in vitro and in vivo. In this study, a total of 10 positive phage clones were obtained from MDA-MB-231 and MCF-7 breast stem cells, and eight and six sequencing results were obtained, respectively. A random positive sequence result for MDA-MB-231 and MCF-7 breast cancer stem cells was selected and the peptides were synthesized. The peptides were subsequently labeled with FITC. The peptides were identified to be specific for breast cancer stem cells. Finally, a breast cancer model was established using MDA-MB-231 breast cancer stem cells in nude mice, and the mice were injected with the FITC-labeled polypeptide B8. The polypeptide B8 FITC labeling with was abundant in the tumor tissue, but not observed in the control liver tissue. This suggested that the polypeptide B8 may be specific to breast cancer cells. However, in this study a breast cancer model in nude mice was not developed by injecting MCF-7 stem cells; therefore, further research in this area is required.

In conclusion, several phage sequences specific to breast cancer stem cells were identified and peptides that can be used, coupled with various drugs and enzymes, to target breast cancer cells or tissues were synthesized. Therefore, these peptides may have broad prospects in the treatment of breast cancer.

\section{Acknowledgments}

The authors would like to thank Dr Wenwen Yu from the Immunoassay Laboratory of Tianjin Medical University, Key Laboratory of Ministry of Education of China (Tianjin, China) for flow cytometric analysis.

\section{Funding}

The present study was funded by The Shandong Province Natural Science Foundation Project (grant no. ZR2014HL076). 


\section{Availability of data and materials}

The datasets used during the present study are available from the corresponding author upon reasonable request.

\section{Authors' contributions}

TL conducted the experiments, data analysis and the writing of the manuscript. BL designed the project and analyzed the data. LZ conducted the experiments. CZ and YJ analyzed the data. YW designed and guided the project. All authors have checked and confirmed the data of the manuscript. All authors read and approved the manuscript and agree to be accountable for all aspects of the research in ensuring that the accuracy or integrity of any part of the work are appropriately investigated and resolved.

\section{Ethics approval and consent to participate}

The experimental protocol was approved by Ethics Committee of Shandong Cancer Hospital and Institute.

\section{Patient consent for publication}

Not applicable.

\section{Competing interests}

The authors declare that they have no competing interests.

\section{References}

1. Feuer EJ, Wun LM, Boring CC, Flanders WD, Timmel MJ and Tong T: The lifetime risk of developing breast cancer. J Natl Cancer Inst 85: 892-897, 1993.

2. So WK, Choi KC, Chan CW and Chair SY: Age-related differences in the quality of life of Chinese women undergoing adjuvant therapy for breast cancer. Res Gerontol Nurs 29-26, 2011.

3. Zhu D, Lam DH, Purwanti YI, Goh SL, Wu C, Zeng J, Fan W and Wang S: Systemic delivery of fusogenic membrane glycoprotein-expressing neural stem cells to selectively kill tumor cells. Mol Ther 21: 1621-1630, 2013.

4. Luo M, Clouthier SG, Deol Y, Liu S, Nagrath S, Azizi E and Wicha MS: Breast cancer stem cells: Current advances and clinical implications. Methods Mol Biol 1293: 1-49, 2015.

5. Hyvönen $M$ and Laakkonen P: Identification and characterization of homing peptides using in vivo peptide phage display. Methods Mol Biol 1324: 205-222, 2015.

6. Tiede C, Tang AA, Deacon SE, Mandal U, Nettleship JE, Owen RL, George SE, Harrison DJ, Owens RJ, Tomlinson DC and McPherson MJ: Adhiron: A stable and versatile peptide display scaffold for molecular recognition applications. Protein Eng Des Sel 27: 145-55, 2014.
7. Ajani JA, Song S, Hochster HS and Steinberg IB: Cancer stem cells: The promise and the potential. Semin Oncol 42 (Suppl 1): S3-S17, 2015

8. $\mathrm{Li} \mathrm{X}$ and Mao C: Using phage as a platform to select cancer cell-targeting peptides. Methods Mol Biol 1108: 57-68, 2014.

9. Wang T, Hartner WC, Gillespie JW, Praveen KP, Yang S, Mei LA, Petrenko VA and Torchilin VP: Enhanced tumor delivery and antitumor activity in vivo of liposomal doxorubicin modified with MCF-7-specific phage fusion protein. Nanomedicine 10: 421-430, 2014.

10. Pouyanfard S, Bamdad T, Hashemi H, Bandehpour M and Kazemi B: Induction of protective anti-CTL epitope responses against HER-2-positive breast cancer based on multivalent T7 phage nanoparticles. PLoS One 7: e49539, 2012.

11. Finlay-Schultz J, Cittelly DM, Hendricks P, Patel P, Kabos P, Jacobsen BM, Richer JK and Sartorius CA: Progesterone downregulation of miR-141 contributes to expansion of stem-like breast cancer cells through maintenance of progesterone receptor and Stat5a. Oncogene 34: 3676-3687, 2015.

12. Lv YG, Wang T, Yuan SF, Li NL, Chen JH, Zhao AZ, Ling R and Wang L: T-vector and in vivo recombination as tools to construct a large antibody library of breast cancer. Hybridoma (Larchmt) 29: 251-254, 2010.

13. Petrenko VA and Jayanna PK: Phage protein-targeted cancer nanomedicines. FEBS Lett 588: 341-349, 2014.

14. Park HY, Lee KJ, Lee SJ and Yoon MY: Screening of peptides bound to breast cancer stem cell specific surface marker CD44 by phage display. Mol Biotechnol 51: 212-220, 2012.

15. Nemudraya AA, Kuligina EV, Ilyichev AA, Fomin AS, Stepanov GA, Savelyeva AV, Koval OA and Richter VA: Selection of antitumor displayed peptides for the specific delivery of the anticancer drug lactaptin. Oncol Lett 12: 4547-4555, 2016.

16. Yang H, Brand JS, Fang F, Chiesa F, Johansson AL, Hall P and Czene K: Time-dependent risk of depression, anxiety, and stress-related disorders in patients with invasive and in situ breast cancer. Int J Cancer 140: 841-852, 2017.

17. Yang F, Xu J, Tang L and Guan X: Breast cancer stem cell: The roles and therapeutic implications. Cell Mol Life Sci 74: 951-966, 2017.

18. Asad AS, Moreno Ayala MA, Gottardo MF, Zuccato C, Nicola Candia AJ, Zanetti FA, Seilicovich A and Candolfi M: Viral gene therapy for breast cancer: Progress and challenges. Exp Opin Biol Ther 17: 945-959, 2017.

19. Alferez DG, Simões BM, Howell SJ and Clarke RB: The role of steroid hormones in breast and effects on cancer stem cells. Curr Stem Cell Rep 4: 81-94, 2018.

20. Wolfe AR and Woodward WA: Breast cancer stem cell correlates as Predicative factors for radiation therapy. Semin Radiat Oncol 25: 251-259, 2015.

21. To K, Fotovati, A, Reipas KM, Law JH, Hu K, Wang J, Astanehe A, Davies AH, Lee L, Stratford AL, et al: Y-box binding protein-1 induces the expression of CD44 and CD49f leading to enhanced self-renewal, mammo-sphere growth, and drug resistance. Cancer Res 70: 2840-2851, 2010

22. Liu F, Qi CL, Kong M, Liu TT, Li L and Li BJ: Screening specific polypeptides of breast cancer stem cells from a phage display random peptide library. Oncol Lett 12: 4727-4731, 2016.

This work is licensed under a Creative Commons Attribution-NonCommercial-NoDerivatives 4.0 International (CC BY-NC-ND 4.0) License. 